DOI: $10.17234 / S R A Z .65 .28$

UDK: 811.134.3'367.625

UDK: 811.134.3(091)

Original scientific paper

Recebido a 28 de março de 2020

Aceite para a publicação a 25 de novembro de 2020

\title{
Funções do pretérito mais-que-perfeito simples em textos literários, históricos e religiosos do galego-português
}

\author{
Márluce Coan \\ Universidade Federal do Ceará - Brasil \\ coanmalu@ufc.br
}

Neste artigo, analisamos os usos do pretérito mais-que-perfeito em textos de prosa literária, histórica e religiosa do galego-português. A forma em -ra ocorre tanto no domínio temporal (expressando passado do passado, passado sequencial e passado cotemporal) quanto no domínio modal (nas funções conjuntiva, condicional e volitiva). Trata-se de atuação condicionada por tipo de verbo, marcador temporal, pessoa discursiva, polaridade e tipo oracional. Ampliamos, portanto, a dimensão explanatória do nível morfossintático para o semântico-discursivo.

Palavras-chave: pretérito mais-que-perfeito; multifuncionalidade; domínio temporal; domínio modal; galego-português.

\section{Considerações iniciais}

Em pesquisas anteriores sobre o pretérito mais-que-perfeito em dados de escrita do Português (Coan 2003; Coan/Lima/Sampaio 2019), verificamos a ocorrência, embora nem sempre haja recorrência, de sua utilização a serviço de seis funções: passado do passado, passado anterior ao momento de fala, passado discursivo, função volitiva, função conjuntiva e função condicional. Esses achados instigaramnos a verificar como o pretérito mais-que-perfeito se comportou outrora, no período medieval, com o intuito de buscar suas funções no período de gestação do português, em que havia uma língua comum galego-portuguesa (conforme Cuesta 1971; Maia 1986; Teyssier 1999, dentre outros). De acordo com Masip (2003: 27), "o galego-português manteve-se como língua oral e escrita entre os fins do século XI e meados do XIV, quando começou a desmembrar-se em português e galego".

Amparados, portanto, pela ideia de unidade no período medieval, selecionamos, para análise, três tipos de prosa: literária, histórica e religiosa, centrando-nos no domínio da funcionalidade da forma -ra. Nessa esteira, a pesquisa preenche uma lacuna investigativa, como aponta Lorenzo (1975: 157): “(...) falta un estudio sistemático de los textos y documentos arcaicos, que podría darnos una visión real de los hechos. (...) En cuanto no se haga esto los cálculos serán provisionales". 


\section{Pressupostos teórico-metodológicos}

Os usos temporais e modais do mais-que-perfeito, no galego-português, segundo Teyssier (1997: 29), são os mesmos do português moderno: há um mais-que-perfeito simples, diretamente herdado do latim, amara (< amaram < amaueram), empregado no sentido temporal (tinha amado) ou modal (amaria). Quanto ao sentido modal, Mattos Silva (1989) verificou usos do mais-que-perfeito em condicionais e em sentenças irrealis em 13,6\% dos dados de uma amostra do século XIV, além de usos correspondentes ao valor temporal de passado do passado. Segundo Xove (1977), no galego das cantigas, a forma em -ra conserva seu valor temporal, salvo em alguns contados casos de modalidade irreal (poderan = poderiam) e outros de imperfeito do subjuntivo $(-r a=-s e)$. Essa leitura modal do mais-que-perfeito, de acordo com Brocardo (2010), já ocorria em Latim, o que, possivelmente, levou ao desuso do mais-que-perfeito simples na atualidade com acepção de passado do passado. Os usos modais de - ra, em lugar do imperfeito do subjuntivo e do condicional, também já foram atestados por Coan (2003) e por Martins/Paiva (2013).

Pode haver, ainda, uso discursivo e volitivo do mais-que-perfeito, conforme atestam Coan/Lima/Sampaio (2019), em que se presta a indicar, respectivamente, um passado no discurso e uma projeção (de desejo ou possibilidade). Coan (2003) e Coan/Lima/Sampaio (2019) verificam, outrossim, que o mais-que-perfeito, às vezes, é utilizado para indicar uma ação passada anterior ao momento de fala e não anterior a outro passado. Conforme Xove (1977), na língua literária do final do século XVIII e dos românticos, já se observava a forma em -ra não como um pluscuamperfecto, mas como um pretérito qualquer do indicativo, por imitação de textos antigos, restaurando-se alguns usos primitivos. Também informa que, no romanceiro velho castelhano, aparece essa forma com valor de perfeito (cf. Szerties 1967 apud Xove 1977).

Em decorrência desses achados na literatura linguística, distanciamo-nos temporalmente, para analisar as funções da forma em -ra no período medieval. Em primeiro lugar, observamos o papel da frequência de cada função, considerandose sua relevância para a configuração gramatical (Bybee 2007), ao desencadear, por exemplo, especialização (um dos princípios de gramaticalização propostos por Hopper 1991). Em seguida, mapeamos os contextos de ocorrência de cada função por tipo de verbo, marcador temporal, pessoa discursiva, polaridade, tipo oracional e gênero textual. A articulação dessas duas etapas fornecerá um esboço do funcionamento do mais-que-perfeito na gestação da língua portuguesa, que teve reflexos ao longo da história.

Tendo em vista nosso interesse pelo período em que galego e português não eram, ainda, línguas autônomas, nosso período de investigação será o arcaico, trovadoresco, antigo ou do galego-português (aproximadamente, de 1214 a 1420, conforme Castro 2006). Independentemente da nomeação, interessa-nos, nesta pesquisa, o período em que, a partir do latim vulgar, galego e português operavam em conjunto como unidade na diversidade, antes de, por razões talvez mais históricas e políticas do que linguísticas, terem desenvolvimentos diferentes. 
Utilizamos três textos para análise: a) um de prosa literária - Crônica troiana [1370-1373]; b) um de prosa histórica - Crônica Geral e Crônica de Castela [1295-1312] e um de prosa religiosa - Milagres de Santiago [1390-1420]. Dada a menor extensão deste (64 folios), para que se equilibrasse o volume textual, tratamos da primeira parte da Crônica Troiana (até o fólio 100 - 239 capítulos) e da primeira parte da Crônica Geral (fólios 1-88 - 176 capítulos). Mesmo com os recortes, obtivemos grande quantidade de dados para análise (1.345 dados), o que atende ao quesito da representatividade para cada obra.

\section{Pretérito mais-que-perfeito simples: uma forma multifuncional}

Conforme se pode verificar na tabela (1), predominam, nos textos analisados, as funções de passado do passado (768 dados), conjuntiva (91 dados) e condicional (141 dados).

Tabela 1: Distribuição das formas em "-ra" por função e por tipo de prosa em dados do galego-português

\begin{tabular}{|l|l|l|l|l|l|l|l|}
\hline $\begin{array}{l}\text { Função } \rightarrow \\
\text { Prosa } \downarrow\end{array}$ & $\begin{array}{l}\text { Passado } \\
\text { do } \\
\text { passado }\end{array}$ & $\begin{array}{l}\text { Passado } \\
\text { sequencial }\end{array}$ & $\begin{array}{l}\text { Passado } \\
\text { conjuntivo }\end{array}$ & $\begin{array}{l}\text { Passado } \\
\text { condicional }\end{array}$ & $\begin{array}{l}\text { Passado } \\
\text { discursivo }\end{array}$ & $\begin{array}{l}\text { Passado } \\
\text { volitivo }\end{array}$ & $\begin{array}{l}\text { Passado } \\
\text { cotemporal }\end{array}$ \\
\hline Literária & 205 & 06 & 80 & 119 & 00 & 03 & 03 \\
\hline Histórica & 377 & 06 & 11 & 21 & 00 & 01 & 07 \\
\hline Religiosa & 186 & 05 & 00 & 01 & 00 & 02 & 00 \\
\hline Totais & 768 & 17 & 91 & 141 & 00 & 06 & 10 \\
\hline
\end{tabular}

Fonte: autoria própria.

Atentemos para o fato de que há uso temporal e modal da forma em -ra. Em relação aos temporais, destacamos os usos como passado do passado, passado sequencial e passado cotemporal, respectivamente ilustrados de (1) a (3). Havia expectativa, também, de uso como passado discursivo, mas não detectamos ocorrência em -ra, apenas dois casos de pretérito perfeito simples (por exemplo, ...cõmo uos ja CÕTEY... - Crônica Troiana).

(1) Et Pares enviou de aly hũ home cõ sua messagẽ al rrey Príamos, dizerlle en cõmo el aly estaua et todo cõmo FEZERA. (Crónica Troiana, folio 24)

(2) Et entõ CHEGARA ja Baldou i et el FEZERA sinal que lle buscase agoa, et Baldou i buscou, andando de huu cabo et do outro, et nõ na pode achar... (Milagres de Santiago, folio 38)

(3) Jazendo o cöde doent[e] VEERA hüu conde de sua terra que ya en romaria a Sanctiago. (Crónica General, folio 49)

Em relação aos usos modais, detectamos vários casos de função conjuntiva (se a noyte nõ fora) e condicional (Almãçor fora preso), ilustradas em (4). Ademais, 
há uso volitivo, conforme exemplo (5). A gama de funções detectadas em galegoportuguês mostra-nos o cenário de outrora, permitindo-nos a visualização de que os usos modais já adentravam o domínio de -ra, o que, certamente, conduziu tal forma ao seu direcionamento atual. O que se percebe é que a dimensão modal foi ganhando espaço, havendo, portanto, conforme Klein-Andreu (1991), reanálise modal de assertividade a não-assertividade, estratégia pragmática para distanciar o falante do conteúdo proposicional. Note-se, também, que é na prosa literária que mais ocorrem as funções modais, gênero no qual há mais situações vinculadas ao desejo, às projeções e às possibilidades.

(4) Et ficou asi a fazenda pola noyte que lles veõ et os partio; ca, se a noyte nõ FORA, Almãçor FORA preso ou morto... (Crónica General, folio 63)

(5) ... et moyto uos UALERA mays de uos yr folgar a hũa jnssoa do mar, ata que esta çerca ouuesse aquela fin que deue de auer. (Crónica Troiana, folio 84)

Quanto aos demais contextos de ocorrência, os linguísticos, os resultados estatísticos seguem na tabela (2).

Tabela 2: Distribuição das formas em "-ra" por função e contexto em dados do galego-português

\begin{tabular}{|c|c|c|c|c|c|c|c|}
\hline $\begin{array}{l}\text { Função } \rightarrow \\
\text { Fatores } \downarrow\end{array}$ & $\begin{array}{l}\text { Passado } \\
\text { do passado }\end{array}$ & $\begin{array}{l}\text { Passado } \\
\text { sequencial }\end{array}$ & $\begin{array}{l}\text { Passado } \\
\text { conjuntivo }\end{array}$ & $\begin{array}{l}\text { Passado } \\
\text { condicional }\end{array}$ & $\begin{array}{l}\text { Passado } \\
\text { discursivo }\end{array}$ & $\begin{array}{l}\text { Passado } \\
\text { volitivo }\end{array}$ & $\begin{array}{l}\text { Passado } \\
\text { cotemporal }\end{array}$ \\
\hline $\begin{array}{l}\text { Tipo } \\
\text { verbal: } \\
\text { Dinâmico } \\
\text { Estativo } \\
\text { Dicendi } \\
\text { Modal }\end{array}$ & $\begin{array}{l}554 \\
165 \\
30 \\
19\end{array}$ & $\begin{array}{l}09 \\
07 \\
- \\
01\end{array}$ & $\begin{array}{l}33 \\
48 \\
- \\
10\end{array}$ & $\begin{array}{l}34 \\
79 \\
- \\
28\end{array}$ & $\begin{array}{l}- \\
- \\
- \\
-\end{array}$ & $\begin{array}{l}- \\
- \\
- \\
06\end{array}$ & $\begin{array}{l}05 \\
03 \\
- \\
02\end{array}$ \\
\hline $\begin{array}{l}\text { Adv. } \\
\text { temporal: } \\
\text { Presença } \\
\text { Ausência }\end{array}$ & $\begin{array}{l}112 \\
656\end{array}$ & $\begin{array}{l}04 \\
13\end{array}$ & $\begin{array}{l}14 \\
77\end{array}$ & $\begin{array}{l}24 \\
117\end{array}$ & - & $\begin{array}{l}01 \\
05\end{array}$ & $\begin{array}{l}04 \\
06\end{array}$ \\
\hline $\begin{array}{l}\text { Pessoa: } \\
\text { P1 } \\
\text { P2 } \\
\text { P3 } \\
\text { P4 } \\
\text { P5 } \\
\text { P6 }\end{array}$ & $\begin{array}{l}02 \\
01 \\
595 \\
02 \\
- \\
168\end{array}$ & $\begin{array}{l}- \\
- \\
14 \\
- \\
- \\
03\end{array}$ & $\begin{array}{l}04 \\
01 \\
73 \\
02 \\
04 \\
07\end{array}$ & $\begin{array}{l}07 \\
01 \\
94 \\
07 \\
02 \\
30\end{array}$ & $\begin{array}{l}- \\
- \\
- \\
- \\
- \\
-\end{array}$ & $\begin{array}{l}- \\
- \\
06 \\
- \\
- \\
-\end{array}$ & $\begin{array}{l}- \\
- \\
- \\
- \\
- \\
01\end{array}$ \\
\hline $\begin{array}{l}\text { Polaridade: } \\
\text { Afirmativa } \\
\text { Negativa }\end{array}$ & $\begin{array}{l}733 \\
35 \\
\end{array}$ & $\begin{array}{l}16 \\
01 \\
\end{array}$ & $\begin{array}{l}46 \\
45\end{array}$ & $\begin{array}{l}112 \\
29 \\
\end{array}$ & - & $\begin{array}{l}06 \\
- \\
\end{array}$ & $\begin{array}{l}10 \\
- \\
\end{array}$ \\
\hline $\begin{array}{l}\text { Tipo oracional: } \\
\text { Parataxe } \\
\text { Hipotaxe } \\
\text { Subordinação }\end{array}$ & $\begin{array}{l}48 \\
146 \\
574 \\
\end{array}$ & $\begin{array}{l}06 \\
04 \\
07\end{array}$ & $\begin{array}{l}02 \\
86 \\
03\end{array}$ & $\begin{array}{l}74 \\
47 \\
20\end{array}$ & $\begin{array}{l}- \\
- \\
-\end{array}$ & $\begin{array}{l}04 \\
02 \\
-\end{array}$ & $\begin{array}{l}02 \\
03 \\
05\end{array}$ \\
\hline
\end{tabular}

Fonte: autoria própria. 
Coan (2003) e Brocardo (2010) atestaram tendência de o mais-que-perfeito permanecer no campo dos verbos modais, sugerindo um processo metafórico de expressão de situações em espaço real para situações do campo psicológico (do desejo, da pretensão). Os dados mostram que a forma em -ra já ocorria nesse campo dos verbos modais, o que pode indicar o processo embrionário da utilização que tem hoje a forma em -ra na oralidade. Também comprovamos nossa hipótese sobre verbos dinâmicos serem predominantes na função temporal de passado do passado; já para as funções modais (volitiva, conjuntiva e condicional), as formas em -ra ocorrem com lexemas modais para a primeira e preferencialmente estativos para as outras duas.

Em relação à presença de marcador temporal, o intuito foi o de verificar se a função temporal de passado do passado, por indicar a noção de passado por si só, ocorreria sem marcador na maioria dos casos. Foi o que verificamos, já que dos 768 usos de -ra como passado do passado, somente 112 estão acoplados a um marcador temporal, ou seja, a maioria ocorre sem marcador (656), conforme demonstra a tabela (2), configurando-se uma relação percentual de $14.58 \%$ versus $85.42 \%$.

Observe-se que, dos usos volitivos, todos são em P3, o que pode já ser um indício de estreitamento paradigmático, conforme Lehmann (1995 [1982]), já que, no processo de mudança, a forma passa a ter menos variabilidade paradigmática. Se há uso frequente em P3, espera-se o mesmo para P6, no entanto, há menos casos devido à homonímia com a P6 do pretérito perfeito simples em português, processo que se difundiu a partir do século XIV. Conforme Maia (1986), as terminações inicialmente distintas -ã <-ant e - ̃ <-unt começam a confundir-se desde o século XIII, mas mais intensamente a partir do século XIV.

Quanto à polaridade, pautamo-nos em Becker (2008), que observou frase negativa como contexto preferencial de uso do mais-que-perfeito nas funções modais. Verificamos que, nas funções temporais, o contexto de base é afirmativo (para passado do passado, sequencial e cotemporal); no entanto, consideramos expressivo o uso das funções conjuntiva e condicional em orações negativas, respectivamente, 45 e 29 dados.

Para os tipos oracionais, seguimos a divisão tripartida em parataxe, hipotaxe e subordinação, na perspectiva de Hopper e Traugott (2003). Primeiramente, observamos que o contexto de subordinação é o preferido quando a função é a de passado do passado, com um detalhamento: das 574 subordinações, 402 ocorrem em contextos especificativos (orações adjetivas). Quanto aos uso modais, com base em Becker (2008) e Mattos e Silva (1989), esperávamos localizar mais dados em contextos hipotáticos, o que de fato ocorreu para a função conjuntiva. Paralelamente, há uso frequente da função condicional em estruturas paratáticas, quando os contextos aventam possibilidades/hipóteses, ou seja, o peso da modalidade irrealis parece se sobrepor ao peso estrutural do tipo de oração, quando se trata de parataxe. 


\section{Considerações finais}

Comprovamos, nesta pesquisa, que a forma em -ra está a serviço de funções temporais (passado do passado, passado sequencial e passado cotemporal) e modais (conjuntiva, condicional e volitiva). Não localizamos, todavia, uso de -ra para codificar o passado discursivo. Nossa pesquisa, outrossim, indicou contextos propícios ao uso de -ra em um ou outro domínio (temporal/modal), dentre os quais destacamos: a) predominância de verbos dinâmicos na função temporal de passado do passado, de verbos modais na função volitiva e de verbos de estado nas funções conjuntiva e condicional; b) tendência a não utilizar marcador temporal na função de passado do passado, pois se sobressai o morfema -ra como indicativo de anterioridade; c) frequência de uso de -ra em P3, a pessoa a que mais se refere, atualmente, a forma -ra, pelo menos no português oral do Brasil; d) contexto de polaridade negativa como propício ao uso modal conjuntivo; e) uso de-ra como passado do passado em estruturas subordinadas, preferencialmente especificativas, e como modal em contextos hipotáticos.

Nossos dados corroboram uma característica importante das gramáticas das línguas naturais, já apontada por Lichtenberk (1991: 38): as gramáticas são um fenômeno histórico, produtos de desenvolvimentos históricos. Os resultados tanto quantitativos quanto qualitativos aqui apresentados fornecem provas sobre o comportamento da forma -ra no período medieval. Trata-se de um estudo sistemático que objetiva preencher uma lacuna investigativa, possibilitando uma visão menos artificial dos feitos históricos.

\section{Bibliografia}

Becker, Martin (2008). From temporal to modal: divergent fates of the Latin synthetic pluperfect in Spanish and Portuguese, in: The Paradox of Grammatical Change: perspectives from romance [U. Detges; R. Waltereit], Amsterdam: John Benjamins, pp. 147-180.

Brocardo, Maria T. (2010). Portuguese pluperfect: elements for a diachronic approach, in: Linguistic Studies, v. 5. Lisboa, pp.117-130.

Bybee, Joan (2007). Frequency of use and the organization of language, Oxford: Oxford University Press.

Castro, Ivo (2006). Introdução à História do Português. Lisboa: Colibri.

Coan, Márluce (2003). As categorias Tempo, Aspecto, Modalidade e Referência na significação dos pretéritos mais-que-perfeito e perfeito: correlação entre função(ões)forma(s) em tempo real e aparente. Tese, Universidade Federal de Santa Catarina.

Coan, Márluce; Lima, Ester V.; Sampaio, Mariana F. (2019). Um retrato do pretérito mais-que-perfeito de 1887 a 2012, D.E.L.T.A., 35-2, pp.1-26.

Cuesta, Pillar V.; Luz, Maria A. M. (1980 [1971]). Gramática da Língua Portuguesa, Lisboa: Edições 70.

Hopper, Paul J. (1991). On Some Principles of Grammaticization, in: Approaches to Grammaticalization [E. Traugott; B. Heine], Amsterdam/Philadelphia: John Benjamins Publishing Co. 
Klein-Andreu, Flora (1991). Losing ground: A discourse-pragmatic solution to the history of -ra in Spanish, in: Discourse Pragmatics (S. Fleischman; L. Waugh), London: Roukedge, pp.164-178.

Hopper, Paul; Traugott, Elizabeth C. (2003). Grammaticalization, Cambridge: Cambridge University Press.

Lehmann, Christian (1995 [1982]). Thought on grammmaticalization, Munich: Lincom Europa.

Lichtenberk, Frantisek (1991). On the Gradualness of Grammaticalization, in: Approaches to Grammaticalization [E. Traugott; B. Heine], Amsterdam/Philadelphia: John Benjamins Publishing Co.

Lorenzo, Ramón (2004). Miragres de Santiago, Valencia: Scriptorium Ediciones Limitadas.

Lorenzo, Ramón (1985). Crónica troiana. Introducción e texto, A Coruña: Fundación Pedro Barrié de la Maza, Conde de Fenosa.

Lorenzo, Ramón (1975). Gallego y Portugués. Algumas semejanzas y diferencias, in: Filología y Didática Hispánica [J. M. Navarro et al.], Hamburg, Romanistik in Geschichte und Gegenwart, Band 1, Helmut Buske Verlag.

Lorenzo, Ramón (1975). La traducción gallega de la Crónica General y de la Crónica de Castilla, Tomo II: Glosario, Ourense: I.E.O.P.F.

Maia, Clarinda A. (1986). História do galego-português, Coimbra: Imprensa da Universidade.

Martins, Kellen C.; Paiva, Maria C. (2013). V-ra no português: uma análise diacrônica, in: Estudos Linguísticos, 42 (1), pp. 540-552.

Masip, Vicente (2003). Gramática histórica portuguesa e espanhola: um estudo sintético e contrastivo, São Paulo: EPU.

Mattos e Silva, Rosa V. (1989). Estruturas trecentistas. Elementos para uma gramática do Português Arcaico, Lisboa: IN-CM.

Teyssier, Paul (1997). História da língua portuguesa, São Paulo, Martins Fontes (Tradução de Celso Cunha).

Xove, Xose (1977). A temporalidade verbal nas "cantigas d'escarnho e de mal dizer", Facultade de Filoloxia. Universidade de Santiago.

\section{Functions of pluperfect in literary, historical and religious texts from Galician-Portuguese}

In this article, we analyze the uses of the pluperfect in Galician-Portuguese from literary, historical and religious texts. The-ra form occurs both in the temporal domain (earlier past, sequential past and cotemporal past) and in the modal domain (conjunctive, conditional and desiderative). It is a performance conditioned by verb type, verbal modifier, discursive person, polarity and clauses type. In addition to attesting the multifunctionality of the form in -ra, we show factors that underlie the use in each function, expanding the explanatory dimension from the morphosyntactic level to the semantic-discursive.

Keywords: pluperfect; multifunctionality; temporal domain; modal domain; GalicianPortuguese. 
